\title{
Migraine in adults with diabetes; is there an association? Results of a population-based study
}

This article was published in the following Dove Press journal: Diabetes, Metabolic Syndrome and Obesity:Targets and Therapy

\author{
Ana López-de-Andrés' \\ José Luis del Barrio' \\ Valentín \\ Hernández-Barrera' \\ Javier de Miguel-Díez ${ }^{2}$ \\ Isabel Jimenez-Trujillo' \\ María Angeles \\ Martinez-Huedo ${ }^{3}$ \\ Rodrigo Jimenez-García \\ 'Preventive Medicine and Public \\ Health Teaching and Research Unit, \\ Health Sciences Faculty, Rey Juan \\ Carlos University, Alcorcón, Madrid, \\ Spain; ${ }^{2}$ Respiratory Department, \\ Hospital General Universitario \\ Gregorio Marañón, Madrid, Spain; \\ ${ }^{3}$ Preventive Medicine and Public \\ Health Department, Teaching and \\ Research Unit, University Hospital La \\ Paz, Madrid, Spain
}

Correspondence: Rodrigo Jimenez-García Preventive Medicine and Public Health Teaching and Research Unit, Health Sciences Faculty, Rey Juan Carlos University, Avda de Atenas s/n, 28922

Alcorcón, Madrid, Spain

Tel +34914888853

Fax +34 9l 4888848

Email rodrigo.jimenez@urjc.es
Aims: To investigate the association between migraine and diabetes mellitus while controlling for several socio-demographic characteristics, comorbidities, and lifestyle variables. We also aimed to identify which of these variables are associated with migraine among diabetics.

Patients and methods: We conducted a cross-sectional study using data taken from the European Health Interview Surveys for Spain conducted in 2009/10 $(n=22,188)$ and 2014 $(n=22,842)$. We selected those subjects $\geq 40$ years of age. Diabetes status was self-reported. One non-diabetic control was matched by the year of survey, age, and sex for each diabetic case. The presence of migraine was defined as the affirmative answer to both of the following questions: "Have you suffered migraine or frequent headaches over the last 12 months?" and "Has your physician confirmed the diagnosis?". Independent variables included demographic and socio-economic characteristics, health status variables, lifestyle, and pain characteristics.

Results: The prevalence of migraine was significantly higher among those suffering from diabetes $(14.9 \%$ vs. $13.0 \%$; $p=0.021)$. The multivariable analysis showed that diabetes was not associated with a higher risk of migraine (adjusted OR 1.06; 95\%CI 0.89-1.25). Among diabetic subjects, female sex, suffering concomitant mental disorders, respiratory disorders, neck pain, and low back pain were variables associated with suffering from migraine.

Conclusion: We found no significant differences in the prevalence of migraine between diabetics and non-diabetic age- and sex-matched controls after controlling for possible confounders.

Keywords: diabetes, headache, survey, self-rated health, comorbidities, pain medication

\section{Background}

Migraine and, in general, headache disorders are recorded among the top ten causes of disability interfering with activities of daily living, ${ }^{1}$ with lifetime prevalence ranging between $14 \%$ and $16 \% .^{2,3}$ In recent years, the prevalence of migraine in Spain has increased from $6.54 \%$ in 2003 to $9.69 \%$ in $2012 .{ }^{4}$ In this study it was found that suffering from any comorbid conditions (including heart disease, high blood pressure, arthritis, asthma, bronchitis, diabetes mellitus, osteoporosis, menopausal symptoms, and depression) increased the risk of suffering from migraine (adjusted OR 2.42; 95\% CI 2.05-2.86). ${ }^{4}$

Diabetes may be relevant in migraine pathophysiology, considering that diabetic patients display changes in vascular reactivity and nerve conduction. ${ }^{5}$ However, the association between migraine and diabetes is controversial. An inverse relationship between diabetes and migraine has been reported in several studies, ${ }^{6,7}$ nevertheless, 
other studies have concluded that the prevalence of migraine has been shown to be similar or higher. ${ }^{8-10}$

Several authors have found that obesity is a risk factor for type 2 diabetes and for migraine and therefore, obesity would be a confounding variable for the association between migraine and diabetes. ${ }^{11,12}$ However, differences in the socio-demographic characteristics, coexisting physical and mental conditions and lifestyles, may explain the association between diabetes and migraine, beside obesity, described by other authors. ${ }^{7-9,13}$

Further investigations are necessary to increase knowledge on the pathophysiology of migraine in people with diabetes, and as a consequence to be able to improve the management of migraine among diabetic patients. ${ }^{6,14}$

In this study, we sought to investigate the association between migraine and diabetes, controlling for a large number of socio-demographic characteristics, comorbidities, and lifestyle variables. We also aimed to identify which of these variables are independently associated with migraine among diabetics.

\section{Patients and methods}

\section{Study design, setting, and participants}

We conducted a cross-sectional study using individualized data taken from the European Health Interview Surveys for Spain (EHSS) conducted in the years 2009/10 $(n=22,188)$ and $2014(n=22,842)$. These surveys cover a representative sample of non-institutionalized adults (aged 15 years or over) residing in main family dwellings (households) in Spain. Information was collected in home-based, computer-assisted, personal interviews conducted from April 2009 to March 2010 for the EHSS 2009/10, and from January to December 2014 for the EHSS2014. The two surveys included different participants. Details on the methodology of these surveys can be found elsewhere. ${ }^{15,16}$ We selected those subjects aged 40 years or over.

\section{Study variables and data sources/ measurement}

The variables included in our study were based on questions identically worded in both surveys.

To identify those with diabetes in our study, we included all subjects who answered affirmatively to either or both of the following questions: "Has your doctor told you that you are currently suffering from diabetes?" and/or "Have you taken any medication to treat diabetes in the last 2 weeks?".

Subjects who answered "No" to both questions were selected to create the control group. A control subject was matched by age, sex, and region of residence for each diabetic case. If more than one control for a case was found, then the control subject was selected randomly.

Individuals were classified as migraine sufferers if they answered "Yes" to both the following questions: "Have you suffered migraine or frequent headaches over the last 12 months?" and "Has your physician confirmed the diagnosis?" This definition of migraine has been used by our group in previous investigations. ${ }^{4}$

We analyzed the following independent variables:

1. demographic and socio-economic characteristics, including; age, sex, nationality (immigrant/Spanish-born), educational level, monthly income, and whether the person interviewed was living with a partner (Yes/No).

2. Health status, including; self-perceived health (very good/ good vs. fair/poor/very poor), self-reported physiciandiagnosed chronic conditions (heart diseases, respiratory diseases, high blood pressure, cancer), mental disorders, and pain (neck pain, low back pain).

3. Lifestyle, including; self-reported body mass index (BMI), physical exercise, tobacco use, and alcohol consumption.

4. Pain characteristics, including; 1) pain intensity using the question: "Overall, during the past 4 weeks, how much physical pain did you have?" The participant was informed this refers to any physical pain he has had during the past 4 weeks. 2) Pain medication; using the question "During the past 2 weeks, have you used any pain medications that were prescribed or recommended to you by a doctor for headache or migraine?".

The questions used to create these variables can be found elsewhere and the categories are shown in Table $1 .{ }^{15-17}$

\section{Statistical methods}

The distribution according to the study variables was described and compared for the diabetic and non-diabetic matched samples. We used proportions and means with SDs as descriptive statistics. We estimated the prevalence of migraine for subjects with and without diabetes. Prevalence was calculated using the study sample; no sample weights were used for estimations.

Bivariate conditional logistic regression models were conducted to compare the distribution and the prevalence between diabetics and their age- and sex-matched controls, according to study variables (demographic and socioeconomic variables, health status variables, and lifestyle, and pain characteristics). 
Table I Distribution of the study population according to demographic and socio-economic variables, health status, lifestyle, and pain characteristics

\begin{tabular}{|c|c|c|c|c|}
\hline Variable & Category & $\begin{array}{l}\text { Diabetes, } \\
\text { N (\%) }\end{array}$ & $\begin{array}{l}\text { No diabetes, } \\
\text { N (\%) }\end{array}$ & $p$-value \\
\hline \multirow[t]{4}{*}{ Age groups } & $40-59$ years & $743(2 \mid .6)$ & $743(21.6)$ & NA \\
\hline & $60-69$ years & $923(26.8)$ & $923(26.8)$ & \\
\hline & $70-79$ years & I,076 (3I.3) & $\mathrm{I}, 076(3 \mathrm{I} .3)$ & \\
\hline & 80 or more & $699(20.3)$ & $699(20.3)$ & \\
\hline Sex & Female & $\mathrm{I}, 843(53.6)$ & $\mathrm{I}, 843(53.6)$ & NA \\
\hline Nationality & Immigrant & $68(2.0)$ & $83(2.4)$ & 0.214 \\
\hline \multirow[t]{3}{*}{ Educational level } & No studies/primary & $2,488(72.3)$ & $2,27 \mid(66.0)$ & 0.001 \\
\hline & Secondary & $665(19.3)$ & $696(20.2)$ & \\
\hline & High education & $288(8.4)$ & $474(13.8)$ & \\
\hline \multirow[t]{3}{*}{ Monthly income } & $<€ 850$ & I, $198(4 \mid .2)$ & $990(35.1)$ & 0.015 \\
\hline & $€ 850-1,400$ & $789(27.1)$ & $734(26.0)$ & \\
\hline & $>€ 1,400$ & $920(31.6)$ & I,097 (38.9) & \\
\hline Living with a partner & Yes & $\mathrm{I}, 92 \mathrm{I}(55.8)$ & I,990 (57.8) & 0.068 \\
\hline Self-rated health & Fair/poor/very poor & $2,384(69.3)$ & I,65I (48.0) & $<0.001$ \\
\hline Respiratory disease $^{\mathrm{a}}$ & Yes & $575(16.7)$ & $416(12.1)$ & $<0.001$ \\
\hline Heart disease $^{\mathrm{b}}$ & Yes & $856(24.9)$ & $505(14.7)$ & $<0.001$ \\
\hline Stroke $^{c}$ & Yes & $205(6.0)$ & $113(3.3)$ & $<0.001$ \\
\hline High blood pressure & Yes & $2,166(62.9)$ & $\mathrm{I}, 485(43.2)$ & $<0.001$ \\
\hline Cancer & Yes & $260(7.6)$ & $196(5.7)$ & 0.002 \\
\hline Mental disorders ${ }^{d}$ & Yes & 771 (22.4) & $574(16.7)$ & $<0.001$ \\
\hline Neck pain & Yes & $1,109(32.2)$ & $921(26.8)$ & $<0.001$ \\
\hline Low back pain & Yes & I,277 (37.I) & $I, 04 I(30.3)$ & $<0.001$ \\
\hline \multirow[t]{3}{*}{ Body mass index } & $<25$ & $678(22.2)$ & $\mathrm{I}, 059(34 . \mathrm{I})$ & $<0.001$ \\
\hline & $25-29.9$ & $1,300(42.6)$ & I,383 (44.6) & \\
\hline & $\geq 30$ & $I, 07 \mid(35.1)$ & $661(21.3)$ & \\
\hline Physical exercise ${ }^{e}$ & $0-3$ days & I,335 (38.8) & $\mathrm{I}, 194(34.7)$ & $<0.001$ \\
\hline \multirow[t]{3}{*}{ Tobacco use } & Current smoker & $477(14.4)$ & $499(15.0)$ & 0.746 \\
\hline & Ex-smoker & $981(29.6)$ & $921(27.7)$ & \\
\hline & Never & $\mathrm{I}, 854(56.0)$ & $\mathrm{I}, 90 \mathrm{I}(57.2)$ & \\
\hline Alcohol consumption ${ }^{f}$ & Yes & I,008 (29.3) & $\mathrm{I}, 404(40.8)$ & $<0.001$ \\
\hline \multirow[t]{3}{*}{ Pain intensityg } & Light & $606(28.5)$ & $633(34.4)$ & 0.010 \\
\hline & Moderate & $790(37.2)$ & $712(38.7)$ & \\
\hline & Intense/extreme & $728(34.3)$ & $496(26.9)$ & \\
\hline Use of pain medication ${ }^{h}$ & Yes & I,649 (47.9) & I,325 (38.5) & $<0.001$ \\
\hline Migraine & Yes & $512(14.9)$ & $448(13.0)$ & 0.021 \\
\hline
\end{tabular}

Notes: ${ }^{a}$ Respiratory diseases included asthma, COPD, and emphysema. 'Heart disease included: coronary disease, myocardial infarction, and angina. 'Stroke included: cerebral infarction, cerebral hemorrhage, and cerebral embolism. 'Mental disorders included anxiety and depression. ePhysical exercise: day per week walking for at least 10 minutes. 'Alcohol consumption: if the subject has consumed alcohol two or more times a month over the last year. ${ }^{8}$ Pain intensity in the last 4 weeks. ${ }^{\mathrm{h} C o n s u m p t i o n}$ of prescribed pain medication in the last 2 weeks.

Abbreviation: NA, not applicable because these are the matching variables.

The Fisher's exact test was used to analyze the association of the study variables with migraine among diabetics.

To assess the association of diabetes with migraine, we conducted a multivariable unconditional logistic regression model. The dependent variable was "migraine yes/ no" and the main independent variable was the presence of diabetes.

Finally, we identified the study variables independently associated with migraine only among subjects suffering from diabetes, by using a multivariable unconditional logistic regression model, once again.

For the multivariable models we included those variables which were statistically significant in the bivariate analysis and those which, although they did not reach the point of statistical significance, were of interest from an epidemiological and health care point of view. The result of the regression model is shown as the OR with $95 \%$ CIs. We checked for interactions in the model. 
Matching and estimations were made using the STATA program and statistical significance was set at two-tailed $\alpha<0.05$.

\section{Ethical aspects}

This study was conducted using an anonymous, publicly accessible dataset and confidentiality was maintained at all times. In accordance with the Spanish legislation, the approval of an ethics committee was deemed unnecessary.

\section{Results}

\section{Study population characteristics}

The prevalence of diabetes among subjects aged 40 years or over was $11.4 \%(1,704)$ for the EHSS 2009 and $11.7 \%$ $(1,876)$ for the EHSS 2014.

Before matching was conducted, the mean age for the diabetic population was 69.6 years (SD 11.6) and 60.4 years (SD 13.7) among those without the disease $(p<0.001)$. The sex distribution was $53.1 \%(1,902)$ and $56.0 \%(15,310)$ females for those with and without diabetes $(p<0.001)$.

We matched a total of 3,441 diabetic subjects with ageand sex-matched controls, representing $95.7 \%$ of the diabetic subjects included in the EHSS 2009 and EHSS 2014.

The distribution of the study population according to demographic and socio-economic variables, health status, lifestyle and migraine characteristics are shown in Table 1.

Subjects with diabetes had a significantly lower educational level and monthly income than their age- and sexmatched non-diabetic controls. Worse self-reported health and all the chronic conditions analyzed showed a higher prevalence among the diabetic group. The prevalence of obesity (BMI $\geq 30$ ) was $35.1 \%$ and $21.3 \%$ for those with and without diabetes, respectively $(p<0.001)$. No differences were found for tobacco use, furthermore, diabetic subjects showed significantly lower figures of frequent physical exercise (physical exercise 4-7 days, 61.2\% among diabetic subjects vs. $65.3 \%$ among non-diabetics) and alcohol consumption.

Pain intensity over the last 4 weeks experienced by diabetic subjects was reported to be "Light" in $28.5 \%$, "Moderate" in 37.2\%, and "Intense/extreme" in 34.3\% of subjects with the corresponding figures for the non-diabetic controls being $34.4 \%, 38.7 \%$, and $26.9 \%(p=0.01)$. Diabetics consumed prescribed pain medication in the last 2 weeks in a $9.4 \%$ higher proportion compared to their matched controls (47.9\% vs. $38.5 \% ; p<0.001)$.
The prevalence of migraine was significantly higher among those suffering from diabetes than their age- and sex-matched non-diabetic controls (14.9\% vs. $13.0 \%$; $p=0.021)$. The corresponding crude OR found was 1.18 (95\%CI 1.02-1.36).

\section{Comparison of diabetic subjects and non- diabetic age- and sex-matched controls}

Table 2 shows the prevalence of migraine among diabetic subjects and non-diabetic controls according to demographic and socio-economic variables.

Besides diabetes status, the highest prevalence was found in the 40-59 year-old age group. Women had higher values than men and the prevalence increased as the educational level and monthly income decreased.

Migraines were significantly more prevalent among diabetics than non-diabetics in women, Spanish-born subjects, and in those in the ">€1,400" monthly income category.

Table 3 reflects the findings when we compare the prevalence of migraine according to health status variables.

Regarding self-reported health, besides diabetes status, those with "Fair/poor/very poor" had $\sim 3$ times more migraines than those with "Very good/good" self-rated health. Besides diabetes status, suffering from respiratory

Table 2 Prevalence of migraine among diabetic subjects and nondiabetic controls according to demographic and socio-economic variables

\begin{tabular}{|c|c|c|c|}
\hline Variable & Category & Diabetic & Non-diabetic \\
\hline \multirow[t]{4}{*}{ Age groups ${ }^{b}$} & $40-59$ years & $122(16.4)$ & $112(15.1)$ \\
\hline & $60-69$ years & $130(14.1)$ & $111(12.0)$ \\
\hline & 70-79 years & $163(15.1)$ & 145 (13.5) \\
\hline & 80 or more & $97(13.9)$ & $80(11.4)$ \\
\hline \multirow[t]{2}{*}{ Sex } & Male & $118(7.4)$ & $111(6.9)$ \\
\hline & Female $^{\mathrm{a}}$ & $394(21.4)$ & $337(18.3)$ \\
\hline \multirow[t]{2}{*}{ Nationality } & Spanish-born ${ }^{\mathrm{a}}$ & $503(14.9)$ & $443(13.2)$ \\
\hline & Immigrant & $9(13.2)$ & $5(6.0)$ \\
\hline \multirow[t]{3}{*}{ Educational level $^{\mathrm{b}}$} & No studies/primary & $402(16.2)$ & $312(13.7)$ \\
\hline & Secondary & $86(12.9)$ & $96(13.8)$ \\
\hline & High education & $24(8.3)$ & $40(8.4)$ \\
\hline \multirow[t]{3}{*}{ Monthly income ${ }^{b}$} & $<€ 850$ & $210(17.5)$ & $140(14.1)$ \\
\hline & $€ 850-1,400$ & $123(15.6)$ & 115 (15.7) \\
\hline & $>€ \mathrm{I}, 400^{\mathrm{a}}$ & $115(12.5)$ & $128(\mid 1.7)$ \\
\hline Living with a & Yes & $277(14.4)$ & $262(13.2)$ \\
\hline partner & No & 235 (I5.5) & $186(12.8)$ \\
\hline Total $^{\mathrm{a}}$ & & $512(14.9)$ & $448(13.0)$ \\
\hline
\end{tabular}

Notes: aSignificant differences $(p<0.05)$ between diabetics and non-diabetics for migraine. Comparisons were conducted using conditional logistic regression. bSignificant association $(p<0.05)$ between the variable and migraine among diabetics. Comparisons were conducted using Fisher's exact test. 
Table 3 Prevalence of migraine among diabetic subjects and nondiabetic controls according to health status variables

\begin{tabular}{|c|c|c|c|}
\hline Variable & Category & $\begin{array}{l}\text { Diabetic, } \\
\text { n (\%) }\end{array}$ & $\begin{array}{l}\text { Non-diabetic, } \\
\text { n (\%) }\end{array}$ \\
\hline \multirow[t]{2}{*}{ Self-rated health ${ }^{\mathrm{b}}$} & Very good/good & $67(6.3)$ & $125(7.0)$ \\
\hline & Fair/poor/very poor & $445(18.7)$ & $323(19.6)$ \\
\hline Respiratory & No & $367(\mid 2.8)$ & $357(11.8)$ \\
\hline disease $^{b}$ & Yes & $145(25.2)$ & $91(21.9)$ \\
\hline \multirow[t]{2}{*}{ Heart disease ${ }^{b}$} & No & $348(13.5)$ & $374(12.7)$ \\
\hline & Yes & $164(19.2)$ & $74(14.7)$ \\
\hline \multirow[t]{2}{*}{ Stroke } & No & $472(14.6)$ & $432(13.0)$ \\
\hline & Yes & $40(19.5)$ & $16(14.2)$ \\
\hline High blood & No & I44 (II.3) & $209(10.7)$ \\
\hline pressure $^{b}$ & Yes & $368(17.0)$ & $239(16.1)$ \\
\hline \multirow[t]{2}{*}{ Cancer } & $\mathrm{No}^{\mathrm{a}}$ & $474(14.9)$ & $414(12.8)$ \\
\hline & Yes & $38(14.6)$ & $34(17.3)$ \\
\hline Mental & No & $26 \mid(9.8)$ & $299(10.4)$ \\
\hline disorders ${ }^{\mathrm{b}}$ & Yes & $25 I(32.6)$ & $149(26.0)$ \\
\hline \multirow[t]{2}{*}{ Neck pain ${ }^{b}$} & No & $194(8.3)$ & $201(8.0)$ \\
\hline & Yes & $318(28.7)$ & $247(26.8)$ \\
\hline \multirow[t]{2}{*}{ Low back pain ${ }^{\mathrm{b}}$} & No & $182(8.4)$ & $208(8.7)$ \\
\hline & Yes & $330(25.8)$ & $240(23.1)$ \\
\hline
\end{tabular}

Notes: aSignificant differences $(p<0.05)$ between diabetics and non-diabetics for migraine. Comparisons were conducted using conditional logistic regression. 'Significant association $(p<0.05)$ between the variable and migraine among diabetics. Comparisons were conducted using Fisher's exact test.

disease, heart disease, high blood pressure, mental disorders, and neck and low back pain were associated with a higher prevalence of migraine compared to those without these diseases.

Migraine was significantly more frequent among diabetics than among people without diabetes in subjects who did not suffer from cancer ( $14.9 \%$ vs. $12.8 \% ; p<0.05)$. No significant differences were found for those who suffered from cancer.

The prevalence of migraine among diabetic subjects and non-diabetic controls according to lifestyle and pain characteristics are shown in Table 4.

When we compared the prevalence of migraine between diabetic subjects and their matched controls, according to the categories of lifestyle variables, a significantly higher prevalence was found for sedentary lifestyle $(18.8 \%$ vs. $16.3 \%)$, never smoker (18.2\% vs. $14.8 \%$ ), and for no alcohol consumption ( $18 \%$ vs. $15.6 \%)$.

Subjects with and without diabetes who walked for at least 10 minutes 4 or more days a week showed a lower prevalence of migraine than more sedentary persons.

People with and without diabetes, who reported suffering from "Severe/extreme" pain in the last 4 weeks and using prescribed pain medication, had a significantly higher prevalence of migraine.
Table 4 Prevalence of migraine among diabetic subjects and nondiabetic controls according to lifestyle and pain characteristics

\begin{tabular}{llll}
\hline Variable & Category & $\begin{array}{l}\text { Diabetic, } \\
\text { n (\%) }\end{array}$ & $\begin{array}{l}\text { Non-diabetic, } \\
\text { n (\%) }\end{array}$ \\
\hline Body mass index & $<25$ & $91(13.4)$ & $133(12.6)$ \\
& $25-29.9$ & $176(13.5)$ & $169(12.2)$ \\
& $\geq 30$ & $166(15.5)$ & $101(15.3)$ \\
Physical exercise $^{\mathrm{b}}$ & $0-3$ days & $25 \mathrm{I}(18.8)$ & $195(16.3)$ \\
& $4-7$ days & $261(12.4)$ & $253(11.3)$ \\
Tobacco use $^{\mathrm{b}}$ & Current smoker $^{\mathrm{a}}$ & $56(11.7)$ & $62(12.4)$ \\
& Ex-smoker & $92(9.4)$ & $84(9.1)$ \\
& Never & $338(18.2)$ & $281(14.8)$ \\
Alcohol & No & $438(18.0)$ & $318(15.6)$ \\
consumption $^{\mathrm{b}}$ & Yes & $74(7.3)$ & $130(9.3)$ \\
Pain intensity $^{\mathrm{b}}$ & Light & $6 I(10.1)$ & $77(12.2)$ \\
& Moderate & $144(18.2)$ & $141(19.8)$ \\
& Severe/extreme & $230(31.6)$ & $140(28.2)$ \\
Use of pain & No & $115(6.4)$ & $139(6.6)$ \\
medication $^{\mathrm{b}}$ & Yes & $397(24.1)$ & $309(23.3)$ \\
\hline
\end{tabular}

Notes: ${ }^{a}$ Significant differences $(p<0.05)$ between diabetics and non-diabetics for migraine. Comparisons were conducted using conditional logistic regression. bSignificant association $(p<0.05)$ between the variable and migraine among diabetics. Comparisons were conducted using Fisher's exact test.

Table 5 Factors associated with migraine among diabetics

\begin{tabular}{lll}
\hline Variable & Category & OR (95\%Cl) \\
\hline Sex & Male & $\mathrm{I}$ \\
& Female & $\mathrm{I} .83(\mathrm{I} .43-2.35)$ \\
Respiratory disease & No & $\mathrm{I}$ \\
& Yes & $\mathrm{I} .59(\mathrm{I} .25-2.02)$ \\
Mental disorder & No & $\mathrm{I}$ \\
& Yes & $2.44(\mathrm{I} .96-3.02)$ \\
Neck pain & No & $\mathrm{I}$ \\
& Yes & $\mathrm{I} .92(\mathrm{I} .50-2.44)$ \\
Low back pain & No & $\mathrm{I}$ \\
& Yes & $\mathrm{I} .33(\mathrm{I} .04-1.69)$ \\
Use of pain medication & No & $\mathrm{I}$ \\
& Yes & $2.23(\mathrm{I} .72-2.89)$ \\
\hline
\end{tabular}

Notes: ORs were estimated using multivariable unconditional logistic regression Only significant variables are shown in the table.

Abbreviation: $O R$, odds ratio.

\section{Multivariable logistic regression model's results}

The results of the multivariable model to assess the association of diabetes with migraine using multivariable unconditional logistic regression showed that, after controlling for possible confounders and discarding interactions, diabetes was not associated with a higher risk of migraine (OR 1.06; 95\% CI 0.89-1.25).

The factors associated with suffering from migraine among diabetics are shown in Table 5. 
Female sex was found to be associated with a higher probability of reporting migraine (OR 1.83; 95\%CI 1.43-2.35). Suffering from a respiratory disease and the presence of mental disorders increased the probability of suffering from migraine.

Among diabetic subjects, those with neck pain had a 33\% higher prevalence of migraine than those without neck pain (OR 1.33; 95\%CI 1.04-1.69), and those with low back pain had a $92 \%$ higher prevalence of migraine than those without low back pain (OR 1.92; 95\%CI 1.50-2.44).

Finally, the use of pain medication over the last 2 weeks increased the risk of reporting migraine by double or more.

\section{Discussion}

Our main finding is that we observed no significant differences in the prevalence of migraine among those with diabetes compared to their age- and sex-matched nondiabetic controls, after controlling for socio-demographic and health-related variables. Also, among factors that we studied in diabetic subjects, female sex, the presence of respiratory disease, mental disorders, and pain (neck and low back pain) were significantly related to migraine prevalence. Furthermore, diabetic subjects reported the frequent use of prescription pain medication.

Several previous studies have been designed to investigate the relation between migraine and diabetes. ${ }^{6-10}$ A separate part of the Nord-Trøndelag Health Study (HUNT) 2 Survey including $\sim 50,000$ people, found that the inverse relation between migraine and diabetes was mainly shown in middleaged and elderly people (OR $0.4 ; 95 \%$ CI $0.2-0.9$ for type 1 diabetes and OR $0.7 ; 95 \%$ CI $0.4-0.9$ for type 2 diabetes) and headache prevalence was reduced in those with a duration of diabetes $\geq 13$ years. ${ }^{6}$ Furthermore, Berge et $\mathrm{al}^{7}$ found that patients using diabetic drugs had an overall reduced prevalence of medically treated migraine when compared with the non-diabetic population (OR 0.72 ; 95\%CI $0.68-0.75$ ), and the prevalence declined with increasing age (OR 0.4-0.6) for all types of diabetes in patients aged 60 to 69 , suggesting the presence of a potent age-related factor in migraine occurrence. These authors concluded that the lower prevalence of migraine is related to diabetic neuropathy, causing less pain as well as reduced cerebrovascular reactivity. ${ }^{6,7}$

Our results agree with Haghighi et al, ${ }^{9}$ who compared 147 patients with type 2 diabetes with data from 150 matched subjects from the general population and observed no significant differences in the prevalence of migraine. In Norway, data from the HUNT 2 and HUNT 3 Surveys found no correlation between migraine and type 2 diabetes, however reported an inverse relationship between migraine and type 1 diabetes (OR 0.47; 95\%CI 0.26-0.96) related to microvascular alterations in patients with type 1 diabetes causing diabetic neuropathy. ${ }^{14}$ Differences found between studies may be related to differences in the inclusion criteria, age distribution, and definitions of both diabetes and migraine.

Female sex has been associated with migraine in the general population and among diabetics. ${ }^{18-20}$ In Spain, the results of national health surveys have shown that the probability of women suffering from migraine is three times higher than for

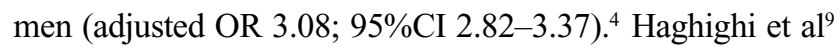
found that the proportion of diabetic women with migraine was $62.5 \%$ compared to only $37.4 \%$ among diabetic men.

Suffering from concomitant respiratory disease increases the probability of reporting migraine 1.59-fold among diabetics. The higher prevalence of migraine among people suffering from asthma and COPD compared to those without these conditions has been described in the general population. $^{21,22}$ Also, we found that diabetics reporting a mental disorder also had significantly higher probabilities of suffering from migraine. Several population surveys have shown a strong association between migraine and depression and/ or anxiety. ${ }^{23,24}$

As we expected, diabetic patients with pain (neck pain and low back pain) had significantly higher probabilities of suffering from migraine. Krein et $\mathrm{al}^{25}$ conducted a cross-sectional study of 993 patients with diabetes and found that $\sim 60 \%$ had chronic pain. Markers of diabetes progression, such as the increased duration of time with diabetes and increased levels of $\mathrm{HbA} 1 \mathrm{c}$, have been independently associated with the presence of chronic back pain, suggesting that uncontrolled diabetes may be a contributing factor to the development of chronic back pain. ${ }^{26}$

The correlation between migraine and obesity remains unclear, some studies have indicated a positive relation, ${ }^{11,27}$ however in population-based studies, BMI was not correlated with the prevalence of episodic migraine. ${ }^{28,29}$ Also, Ford et al ${ }^{11}$ and Le et $\mathrm{al}^{30}$ concluded that subjects who are underweight are more likely to have an elevated risk for migraine. In our study, obesity was not significantly related to migraine prevalence among diabetics.

The surprising finding that non-smokers and teetotalers have a higher prevalence of migraine, since both smoking and alcohol have been described as potential triggers for migraine attack, could be a consequence of a reporting bias, because subjects who have a history of migraine may be avoiding smoking and alcohol altogether due to fear of a potential attack of migraine. 
The frequent need for pain medication has been reported among diabetics. ${ }^{25}$ In the USA, $78 \%$ of diabetic patients with chronic pain reported using pain medication on either a regular or occasional basis. ${ }^{25}$ In our study, the need for pain medication increased the probability of reporting migraine 2.23-fold among diabetics.

The strength of this study is the large, unselected population with a matched design to avoid the confounding effect of age and sex, and the potential to analyze an important number of socio-demographic characteristics, comorbidities, and lifestyle variables that are not available in the clinical setting. However, this study has a series of limitations which must be discussed. First, the causality issue could not be properly addressed because this was a cross-sectional study. Second, self-reporting is the only source for assessing information on migraine, therefore under- or over-reporting may appear from recall, information or social desirability biases. Third, in the multivariate analyses, we were able to adjust for a large number of potential confounding factors, but the possibility of residual confounding by unrecognized factors cannot be ruled out. Fourth, the characteristics of diabetes are not collected in the EHSS, including the type of diabetes, duration, treatment, and chronic complications. Regarding treatment of diabetes, there is controversy over whether it is diabetes itself or the use of oral diabetes medications which might cause a protective effect on migraine. ${ }^{7,31}$ Fifth, the validity of the self-reported conditions included in the EHSS has not been evaluated. However, for diabetes, a study conducted in Spain reported specificities $>95 \%$ and sensitivities $>70 \%$ using medical records as the gold standard..$^{32}$ Finally, the response rates for the EHSS 2009 and 2014 were $\sim 65 \%$ and $61 \%$, respectively, therefore, the existence of a selection bias must be considered. ${ }^{15,16}$

\section{Conclusion}

In conclusion, we observed no significant differences in the prevalence of migraine between those with diabetes and nondiabetic age- and sex-matched controls after controlling for possible confounders. Among diabetic subjects, female sex, suffering from concomitant mental or respiratory disorders or pain (neck and low back), were associated with suffering from migraine.

\section{Availability of data and material}

These databases can be downloaded freely and without cost from the website of the Ministry of Health, Social Services, and Equality (https://www.msssi.gob.es/estadEstudios/estadisticas/EncuestaEuropea/home.htm).
In any case we consider that all relevant data are within the paper.

\section{Acknowledgments}

This study is a part of research funded by the FIS (Fondo de Investigaciones Sanitarias - Health Research Fund, grant number PI16/00564, Instituto de Salud Carlos III); co-financed by the European Union through the Fondo Europeo de Desarrollo Regional (FEDER, 'Una manera de hacer Europa'); and by the Grupo de Excelencia Investigadora URJC-Banco Santander N³0VCPIGI03: Investigación traslacional en el proceso de salud - enfermedad (ITPSE).

\section{Author contributions}

All authors contributed toward data analysis, drafting and revising the paper and agree to be accountable for all aspects of the work.

\section{Disclosure}

The authors report no conflicts of interest in this work.

\section{References}

1. Leonardi M. Burden of migraine: what should we say more? Neurol Sci. 2015;36 Supp1 1:1-3.

2. Stovner LJ, Andree C. Prevalence of headache in Europe: a review for the Eurolight project. J Headache Pain. 2010;11(4):289-299.

3. Stovner Lj, Hagen K, Jensen R, et al. The global burden of headache: a documentation of headache prevalence and disability worldwide. Cephalalgia. 2007;27(3):193-210.

4. Fernández-de-las-Peñas C, Palacios-Ceña D, Salom-Moreno J, et al. Has the prevalence of migraine changed over the last decade (2003-2012)? A Spanish population-based survey. PLoS One. 2014;9(10):e110530.

5. Casucci G, Villani V, Cologno D, D’Onofrio F. Migraine and metabolism Neurol Sci. 2012;33 Suppl 1:S81-85.

6. Aamodt AH, Stovner LJ, Midthjell K, Hagen K, Zwart JA. Headache prevalence related to diabetes mellitus. The Head-HUNT study. Eur J Neurol. 2007;14(7):738-744.

7. Berge LI, Riise T, Fasmer OB, et al. Does diabetes have a protective effect on migraine? Epidemiology. 2013;24(1):129-134.

8. Burch RC, Rist PM, Winter AC, et al. Migraine and risk of incident diabetes in women: a prospective study. Cephalalgia. 2012;32(13): 991-997.

9. Haghighi FS, Rahmanian M, Namiranian N, et al. Migraine and type 2 diabetes; is there any association? J Diabetes Metab Disord. 2016;15(1):37.

10. Split W, Szydlowska M. Headaches in non insulin-dependent diabetes mellitus. Funct Neurol. 1997;12(6):327-332.

11. Ford ES, Li C, Pearson WS, et al. Body mass index and headaches: findings from a national sample of US adults. Cephalalgia. 2008;28(12):1270-1276.

12. Peterlin BL, Rapoport AM, Kurth T. Migraine and obesity: epidemiology, mechanisms, and implications. Headache. 2010;50(4):631-648.

13. Bigal ME, Kurth T, Santanello N, et al. Migraine and cardiovascular disease: a population-based study. Neurology. 2010;74(8):628-635.

14. Hagen K, Åsvold BO, Midthjell K, et al. Inverse relationship between type 1 diabetes mellitus and migraine. Data from the Nord-Trøndelag Health Surveys 1995-1997 and 2006-2008. Cephalalgia. 2018;38(3): $417-426$. 
15. Instituto Nacional de Estadistica. European Health Interview Survey for Spain, 2009. Spain: Instituto Nacional de Estadistica; 2009. Available from: http://www.ine.es/metodologia/t15/t153042009.pdf. Accessed June 5, 2018.

16. Instituto Nacional de Estadistica. European Health Interview Survey for Spain, 2014. Spain: Instituto Nacional de Estadistica; 2014. Available from: http://www.ine.es/metodologia/t15/t153042014.pdf. Accessed June 5, 2018.

17. European Commission [homepage on the Internet]. Eurostat: The European Health Interview Survey. 2006-2018. Available from: http:// ec.europa.eu/eurostat/web/microdata/european-health-interview-survey. Accessed June 5, 2018.

18. Lipton RB, Stewart WF, Diamond S, Diamond ML, Reed M. Prevalence and burden of migraine in the United States: data from the American Migraine Study II. Headache. 2001;41(7):646-657.

19. Straube A, Aicher B, Förderreuther S, et al. Period prevalence of self-reported headache in the general population in Germany from 1995-2005 and 2009: results from annual nationwide population-based cross-sectional surveys. J Headache Pain. 2013;14:11.

20. Lebedeva ER, Kobzeva NR, Gilev DV, Olesen J. Factors associated with primary headache according to diagnosis, sex, and social group. Headache. 2016;56(2):341-356.

21. Aamodt AH, Stovner LJ, Langhammer A, Hagen K, Zwart JA. Is headache related to asthma, hay fever, and chronic bronchitis? The Head-HUNT Study. Headache. 2007;47(2):204-212.

22. Wang X, Xing Y, Sun J, et al. Prevalence, associated factors, and impact on quality of life of migraine in a community in northeast China. J Oral Facial Pain Headache. 2016;30(2):139-149.
23. Fuller-Thomson E, Jayanthikumar J, Agbeyaka SK. Untangling the association between migraine, pain, and anxiety: examining migraine and generalized anxiety disorders in a Canadian population based study. Headache. 2017;57(3):375-390.

24. Song TJ, Cho SJ, Kim WJ, et al. Anxiety and depression in probable migraine: a population-based study. Cephalalgia. 2017;37(9):845-854.

25. Krein SL, Heisler M, Piette JD, Makki F, Kerr EA. The effect of chronic pain on diabetes patients' self-management. Diabetes Care. 2005;28(1):65-70.

26. Rinaldo L, McCutcheon BA, Gilder H, et al. Diabetes and Back Pain: Markers of Diabetes Disease Progression Are Associated With Chronic Back Pain. Clin Diabetes. 2017;35(3):126-131.

27. Peterlin BL, Rosso AL, Rapoport AM, Scher AI. Obesity and migraine: the effect of age, sex and adipose tissue distribution. Headache. 2010;50(1):52-62.

28. Bigal ME, Liberman JN, Lipton RB. Obesity and migraine: a population study. Neurology. 2006;66(4):545-550.

29. Winter AC, Berger K, Buring JE, Kurth T. Body mass index, migraine, migraine frequency and migraine features in women. Cephalalgia. 2009;29(2):269-278.

30. Le H, Tfelt-Hansen P, Skytthe A, Kyvik KO, Olesen J. Association between migraine, lifestyle and socioeconomic factors: a populationbased cross-sectional study. J Headache Pain. 2011;12(2):157-172.

31. Smith B, Ang D. Metformin: potential analgesic? Pain Med. 2015;16(12): 2256-2260.

32. Huerta JM, Tormo MJ, Egea-Caparrós JM, Ortolá-Devesa JB, Navarro C. Accuracy of self-reported diabetes, hypertension and hyperlipidemia in the adult Spanish population. DINO study findings. Rev Esp Cardiol. 2009;62(2):143-152.

\section{Publish your work in this journal}

Diabetes, Metabolic Syndrome and Obesity: Targets and Therapy is an international, peer-reviewed open-access journal committed to the rapid publication of the latest laboratory and clinical findings in the fields of diabetes, metabolic syndrome and obesity research. Original research, review, case reports, hypothesis formation, expert opinion and commentaries are all considered for publication. The manuscript management system is completely online and includes a very quick and fair peer-review system, which is all easy to use. Visit http://www.dovepress.com/testimonials.php to read real quotes from published authors. 